\title{
A CRIANÇA QUEIMADA NUMA UNIDADE NÃO ESPECIALIZADA DE HOSPITAL GERAL
}

\author{
Eni de Jesus Rolim* \\ Marcus Antonio da Silva Leme**
}

ROLIM, E. de J. \& LEME, M. A. da S. A criança queimada numa unidade não especializada de hospital geral. Rev. Esc. Enf. USP, São Paulo, 14(2):139-146, 1980.

A necessidade de melhorar os cuidados de enfermagem para crianças queimadas, inter-. nadas em unidade pediátrica de hospital geral, levou os autores a adaptar rotinas para solução do problema. Os resultados foram bons e se pôde constatar: evolução mais rápida dos pacientes, aumento de interesse do pessoal pelos pacientes, diminuição do tempo gasto na execução dos cuidados.

\section{INTRODUÇÃO}

O hopital-escola, de duzentos leitos, usado por alunos da Escola de Enfermagem da PUC-SP, abriga uma população com diagnósticos os mais diversos, não contando com unidade especial para queimados, apesar de não serem raros os pacientes com tal problema, principalmente crianças.

Sendo a Clínica Pediátrica nosso local de ação, decidimos adaptar cuidados para essas crianças, procurando instalar precariamente uma unidade para queimados, a fim de melhorar o atendimento e estabelecer rotinas, com os poucos recursos disponíveis.

O primeiro cuidado foi a escolha das instalaçôes, utilizando a planta física já existente. Optamos por uma enfermaria situada em frente a um banheiro, deixando-o para exclusivo uso das crianças queimadas, com prescrição de balneoterapia; a enfermaria está situada ao lado do posto e sala de serviços de enfermagem, para maior vigilância e funcionalidade.

Há aproximadamente dois anos, vimos seguindo esse esquema, e a enfermaria se manteve com, no máximo, três pacientes. Até o momento, oito pacientes foram tratados, um deles apresentando $50 \%$ de área queimada, e outro, $65 \%$. A primeira já está fazendo as plásticas de reparação e a segunda está em fase de enxertia, faltando a reepitelização de uma área de aproximadamente $27 \%$; as demais já tiveram alta, com melhora relativa, ou seja, em condições de voltar novamente a uma vida normal.

Enfim, toda criança queimada, embora em área pequena, é tratada dentro do esquema estabelecido, independente da gravidade do quadro.

* Professor Assistente Doutor da disciplina Enfermagem Pediátrica, da Faculdade de Enfermagem da PUC-SP em Sorocaba.

* * Professor da disciplina Enfermagem Cirúrgica, do Colégio Técnico "Professor João Carrozzo", e Supervisor da Clínica Cirúrgica do Hospital de Ensino Sáo Francisco, da Casa de Nossa Senhora da Paz - Açäo Social Franciscana, em Bragança Paulista. 
O motivo de relatar essa experiência é colocar à disposição de colegas, em situações semelhantes, algumas sugestões que talvez possam ajudar a resolver problemas de atendimento de enfermagem a pacientes queimados, em hospitais desprovidos de condições para tal.

Nosso objetivo, ao estabelecer normas de tratamento especiais para o queimado, dentro de uma Clínica Pediátrica, foi o de melhorar o atendimento de enfermagem a essas crianças, diminuindo o tempo de hospitalização e os traumatismos psíquicos sofridos pelos pequenos pacientes, nessas circunstâncias.

\section{FUNDAMENTAÇÃO}

\section{Considerações Gerais}

A finalidade do tratamento é minorar os efeitos da queimadura, o mais rápido possível. As técnicas assépticas devem ser utilizadas enquanto se avalia o paciente queimado e, até que seja estabelecida a terapêutica, as feridas são consideradas abertas e contaminadas.

Para que possamos avaliar adequadamente uma região queimada, temos de seguir algumas etapas, por nós consideradas iniciais, que colocamos na seguinte ordem: registro de sinais vitais, controle hídrico e de diurese, condições de permeabilidade das vias aéreas, gravidade da queimadura.

\section{Gravidade da Queimadura (Etiologia)}

A gravidade da queimadura depende de fatores como: extensão, profundidade, localização anatômica, idade do paciente, etiologia e patologias pré-existentes.

A extencão da área queimada interfere na gravidade do quadro, pois, quanto maior a área, maiores serão as perdas sofridas pelo paciente. Usa-se geralmente a chamada "Regra dos Nove" para indicar a porcentagem da queimadura, conforme tabela abaixo: ("Guide to Initial therapy of Burns" Subcomnittee on Burns of the Committee on Trauma, of the American Colleege of Surgeons, Bullétin of the A.C.S., May, June, 1964).

\begin{tabular}{lccc}
\hline & Adulto & Lactente & Criança \\
\hline cabeça & $9 \%$ & $19 \%$ & $19-$ idade $\%$ \\
pescoç & $1 \%$ & $1 \%$ & $1 \%$ \\
tronco face posterior & $18 \%$ & $18 \%$ & $18 \%$ \\
tronco face anterior & $18 \%$ & $18 \%$ & $18 \%$ \\
membro superior esquerdo & $9 \%$ & $9 \%$ & $9 \%$ \\
membro superior direito & $9 \%$ & $\mathbf{9} \%$ & $\mathbf{9} \%$ \\
membro inferior esquerdo & $18 \%$ & $13 \%$ & $13 \%+$ idade $2 \%$ \\
membro inferior direito & $18 \%$ & $13 \%$ & $\mathbf{1 3} \%+$ idade 2\% \\
\hline
\end{tabular}

Um outro fator importante na avaliação da gravidade de uma lesão térmica é a profundidade e esta está diretamente relacionada com a etiologia, o aspecto e o enxerto das lesões. Damos abaixo, como exemplo, os principais agentes de queimaduras no organismo humano: 
- Soluções aquosas ferventes como: chá, café, caldo de feijão, etc. geralmente provocam queimaduras superficiais. etc.

- Soluções oleosas como: óleos e derivados do petróleo, óleo de cozinha,

- Agentes químicos como: produtos de laboratório e materiais usados na agricultura $\mathrm{e}$ indústria, que causam queimaduras de diferentes graus.

- Eletricidade, agente que pode atingir grande profundidade e cujos danos poderão aparecer apenas depois de alguns dias. A corrente elétrica provoca necrose em locais distantes do inicialmente afetado. profundas.

Metais quentes e chamas de qualquer espécie provocam queimaduras

Não podemos também deixar de lado os tecidos sintéticos usados no vestuário, que também são responsáveis em grande parte pelo agravamento de lesões térmicas.

Conforme as regiões anatômicas atingidas, as queimaduras podem ser mais ou menos graves; mãos, pés, órgãos genitais e grandes articulações são consideradas áreas que podem comprometer a funcionalidade e movimentação dos membros ou pode interferir severamente em sua auto-imagem.

Está comprovado fisiologicamente que o paciente com idade abaixo dos dezoito meses e acima de sessenta e cinco anos corre maiores riscos em decorrência de queimaduras.

Pela aceleração do metabolismo, as crianças apresentam um processo mais rápido de cicatrização do que o adulto.

sss

É de grande importância ressaltar que a lesão cutânea é apenas um dos aspectos da patologia e que os efeitos desta agressão podem ser sentidos em todo o organismo, a curto, médio e longo prazo.

$\mathrm{O}$ quadro de queimaduras pode ser agravado por qualquer problema de saúde, apresentado pelo indivíduo, antes de sofrer o acidente. Exemplos: anemias, problemas respiratórios e circulatórios, insuficiência renal, doenças metabólicas e degenerativas.

\section{Tratamento de Urgência}

0 tratamento de urgência deve ser precedido de uma breve história da queimadura, inclusive das circunstâncias em que ocorreu a mesma (ar livre, ambiente fechado); também há necessidade de se saberem quais são as características da mesma (água fervente, chama, objeto incandescente, choque elétrico, etc.); um outro fator importante na história é o tempo decorrido desde o momento do acidente até os primeiros cuidados e o tratamento recebido antes da chegada ao hospital, bem como as enfermidades prévias que interferem no planejamento de cuidados a serem dados ao paciente. 
O combate à dor e profilaxia do tétano são imprescindiveis e é de grande importância delimitar a área atingida e o peso do paciente.

A manutenção de via venosa para infusão de líquidos é tão importante quanto a instalação de controle hídrico rigoroso, por meio de cateterismo vesical, e controle hidrelétrolítico.

Dependendo da queimadura, devemos prestar cuidados locais, em geral através de limpeza suave, com soro fisiológico morno, evitando-se o emprego de substâncias locais químicas ou tóxicas. Há necessidade de manter a queimadura seca e, sempre que possivel, exposta; curativo, se existir, deve ser fechadd e contensivo, em seguimentos corpóreos cilíndricos; se o paciente estiver traqueostomizado, planejar cuidados de enfermagem específicos.

A reposição de líquidos é feita em dois períodos:

- o primeiro período de vinte e quatro horas:

- colóides (plasma ou sangue)

— cristalöides

- manutenção hídrica

- se o paciente entrar em acidose, o cálculo para hidratação será: em quantidade igual à porcentagem da queimadura (até $50 \%$ ), multiplicado pelo peso.

em quantidade igual à porcentagem da queimadura, multiplicado pelo peso.

sempre que possível, será feita por via oral, com reidratantes ou solução haldame gelada, cuja composição é:

$\begin{array}{lrl}\text { água } & 1000 \mathrm{ml} \\ \mathrm{NaCl} & 1,5 \mathrm{~g} \\ \mathrm{NaHCO}_{3} & 3,5 \mathrm{~g}\end{array}$

0,15 multiplicado pelo peso, multiplicado pela porcentagem da queimadura.

- segundo período de vinte e quatro horas posteriores:

metade do volume de colóides e cristalóides mais o volume integral de soro glicosado a $5 \%$ (observar para não superhidratar). 0 paciente, mesmo com terapêutica bem instituída, deve ficar sob cuidadosa observação.

\section{CUIDADOS DE ENFERMAGEM}

$\mathrm{Na}$ evolução de enfermagem não podemos nos esquecer de verificar o ritmo e caráter do pulso, pressão arterial, débito urinário, grau de sensibilidade táctil, atitude assumida pelo paciente, controle de peso, ocorrência de vômitos, pressão venosa central, antibióticos quando prescritos. 
Abaixo, damos o planejamento dos cuidados de enfermagem, de acordo com as necessidades básicas afetadas.

1. Na fase aguda.

Necesidades

básicas afetadas

1. Segurança física

2. Equilíbrio das

funçốes vitais

3. Higiene e integridade do revestimento cutâneo-mucoso.

4. Equilíbrio hidreletrolítico

5. Eliminação urinária

2. Na fase crônica

Necesidades

básicas afetadas

1. Segurança física
Cuidados de enfermagem

Providenciar medicação prescrita. Dar apoio psicológico tentando obter colaboração do paciente, para evitar desnecessários traumatismos (agitação, medo e dor).

Usar campos estéreis para cobrir o paciente e mantêlo em condições assépticas o máximo possível.

Se possivel, mudar o decúbito a cada duas horas.

Permitir a presença, na cabeceira do leito, de pessoa estritamente ligada à criança.

Controlar os sinais vitais e a pressão venosa a cada hora. Caso haja necessidade de traqueostomia, manter a aspiração freqüente.

Fazer a limpeza das áreas íntegras com água e sabão e das áreas afetadas, se possível com soro fisiológico morno, não esquecendo de higienizar os cabelos e unhas (solução de continuidade e sujidade na pele e anexos).

Instalação de venoclise com solução prescrita.

Observação da área de instalação de soro, com controle horário de gotejamento (que pode atingir até 200 gotas por minuto). Se houver dissecação de veia, observar as condições locais do mesmo. Administrar líquidos por via oral (se possivel) e controle de quantidade ingerida, pois há desequilíbrio hidreletrolítico e sede intensa.

Passagem de sonda vesical de demora e controle de diurese (volume horário ou até volume minuto conforme o necessário), pois o paciente pode entrar em oligúria ou anúria.

\section{Cuidados de enfermagem}

Do ambiente, fazendo limpeza terminal diária de paredes, janelas, cama, mesa de cabeceira, outros objetos e utensílios no quarto. 
2. Equilibrio das funções vitais

3. Higiene $e$ integridade do revestimento cutâneo-mucoso.

4. Equilíbrio hidreletrolítico

\section{Alimentação}

6. Eliminação urinária e fecal.

\section{Terapêutica}

8. Segurança psicológica
Da roupa de cama.

Fazer pacotes para esterilização, contendo roupas suficientes para vinte e quatro horas.

Um exemplo de conteúdo de pacote:

- dois lençóis;

- quatro lençóis móveis;

- duas calças de pijama ou blusas (conforme área queimada);

- duas ou mais fronhas, ou conforme o necessário;

- uma toalha de banho.

Manter o quarto livre de insetos nocivos (moscas, baratas, formigas, etc.).

Verificar os sinais vitais a curtos intervalos, principalmente a temperatura corpórea.

Fazer a higiene corporal e oral do paciente, inclusive de cabelos e unhas.

Observar cuidadosamente as áreas queimadas descobertas, evitando sujidade e deposição de tecidos, restos de alimentos, etc...

Observar as regiões da pele sã e possível inicio de formação de escaras de decúbito $e$, se houver presença de eritema de pele por compressão no leito, adotar medidas profiláticas.

Manter o paciente na posição prescrita, usando talas, ataduras, coxins, travesseiros, etc...

Hidratar o paciente intensamente por via oral, se possível com água, hidrax, nidex ou suco, conforme a aceitação, a intervalos de trinta minutos.

Observar a hidratação intravenosa, mantendo a velocidade prescrita de soro e observando o local de inserção da agulha, com ou sem dissecção da veia.

Alimentação hiperprotéica hipercalórica e fracionada.

Controlar rigorosamente a diurese, através de sonda vesical já instalada.

Observar a defecação e prevenir obstipação intestinal.

Administrar medicação prescrita, rigorosamente.

Manter constante o pessoal que cuida da criança, evitando excessivo contato com pessoas estranhas.

Orientar a família sobre a evolução do estado do paciente, permitindo acesso diário à enfermaria.

Providenciar recreação adequada à idade, dando especial atenção à higienização dos brinquedos. 
Necesidades

básicas afetadas

1. Segurança física

2. Higiene e integridade cutâneo-mucosa

3. Eliminação

4. Movimentação e atividades

5. Segurança psicológica.

\section{Cuidados de enfermagem}

Tomar cuidado para que as regiōes de epitelização não sejam traumatizadas.

Manter a higiene do ambiente.

Manter a higiene do paciente de forma a diminuir ao máximo a possibilidade de contaminação.

Se for feita limpeza cirúrgica da área queimada, com previsão de enxertia para o dia seguinte, não permitir que sejam colocadas gazes sobre a ferida.

Continuar a observação rigorosa das eliminações: evacuação, diurese, vômito, presença de secreção nas feridas.

Continuar a manter as posições prescritas com o mesmo rigor.

Os segmentos íntegros ou com lesões já cicatrizadas devem ser mantidos em atividade por meio de: massagem, exercícios ativos e passivos.

Preparar o paciente psicologicamente para balneoterapia e executá-la dentro dos padrões prescritos.

Continuar a permitir livre acesso de familiares à enfermaria e mantê-los informados das ocorrências sofridas pelo paciente.

\section{RESULTADOS OBTIDOS}

Após algum tempo do estabelecimento da rotina para o cuidado de enfermagem da criança queimada, foi possível observar melhora em diversos aspectos do funcionamento da unidade.

$O$ pessoal de enfermagem, devidamente treinado para a execução das rotinas estabelecidas, sentiu-se motivado e o interesse pelo tipo especial de pacientes foi revelado pela dedicação e esmero com que se cumpriram as ordens especiais. Embora não possamos precisar numericamente, observamos que a criança tratada na unidade de Pediatria permanecia menos tempo no hospital do que a tratada na unidade de Cirurgia, onde não foi estabelecido esquema especial de tratamento para queimados.

Observou-se que a criança vinda para a unidade de Pediatria, procedente de outros locais, reagia mal, de início, à balneoterapia, preferindo fazer a limpeza cirúrgica. Após algum tempo, verificou-se o inverso. A criança aceitava bem a balneoterapia, passando a preferi-la à limpeza cirúrgica. 
O aumento de atenção dada à criança trouxe a esta maior segurança psicológica e o pessoal de enfermagem maior conhecimento das capacidades e limitações do paciente, quanto à suplência de suas necessidades, dentre outras, de movimentação e recreação.

Ao ser admitida a criança na enfermaria, nos incumbiamos de transmitir aos pais todas as informações necessárias, inclusive quanto à possibilidade de sua permanência ao lado do leito.

Apesar disso, apenas uma família acompanhou de perto a recuperação da criança. Os outros apareciam esporadicamente no hospital; não podemos afirmar se a condição sócio-econômica muito baixa e a distância hospital-residência influenciaram essa ausência.

\section{Agradecimento}

Agradecemos aos Dr. Hamilton Aleardo Gonella e ao Dr. Afonso Carlos Finamor, auxiliares de ensino da Clínica Cirúrgica da Faculdade de Medicina da PUC - SP, em Sorocaba, os quais nos orientaram quanto ao tratamento de urgência; agradecemos, também, à Enfermeira Maria Celina Tarallo, responsável pela Unidade de Pediatria, que colaborou conosco no estabelecimento das rotinas para o tratamento dos queimados.

ROLIM, E. de J. \& LEME, M. A. da S. The children with burns admitted to a Pediatric Unit of a General Hospital. Rev. Esc. Enf. USP, São Paulo, 14(2):139-146, 1980.

The necessity of improving nursing care to children with burns, admitted to a Pediatric Unit of a General Hospital, led the authors to adapt the ward so as to have one room prepared for such children. Results were good. They can be proved by the quicker evolution of the patients' condition, the increased interest of nursing personnel in caring for such patients and in the decreasing time splent by them in the accomflish ment of their tashs.

\section{BIBLIOGRAFIA}

ARTZ, C. P. \& MONCRIEF, J. A. Tratamento de queimaduras. 2. ed. México, Interamericana, 1972. CRUZ, A. O. da \& NIGUTTI, J. F. O. Eliminação de odores em unidade de queimados. Rev. Bras. Enf., Rio de Janeiro, 24(3-4): 176, abr./jun. 1971

GOTO, M. Organização de um serviço para queimados. Rev. paul. Hosp., Sāo Paulo, y(11): 24, nov. 1959. Organização de um serviço para queimados. Rev. paul. Hosp., São Paulo, 7(12): 24, dez. 1959. MEleGA, J. M. Queimaduras. ARS Curandi, São Paulo, $7(7)$ : 6, set. 1974.

MULLER, L. \& CRUZ, A. O. da. Balneoterapia do paciente queimado: sistematização do atendimento de enfermagem. Ent. Novas Dimens. São Paulo, 2(1): 24-7, mar./abr. 1976.

NATIVIDADE, E. M. Como escrever um trabalho científico. Rev. Hosp. Clin., São Paulo, 24(1): 77, jan./fev. 1968.

RUSSO, A. do C. Tratamento das queimaduras. 2. ed. São Paulo, Sarvier, 1976.

STAPE, D. B. \& MULLER, M. de L. G. Contribuição da enfermagem na recuperação do paciente. Rev. Bras. Enf., Rio de aJneiro, 20(4): 264, ago. 1967... 